\title{
Retinoic acid modifies mesodermal patterning in early Xenopus embryos
}

\author{
A. Ruiz i Altaba and T. Jessell \\ Howard Hughes Medical Institute, Center for Neurobiology and Behavior, Columbia University, New York, New York \\ 10032 USA
}

Treatment of early Xenopus embryos with retinoic acid (RA) produces a concentration-dependent series of defects in anterior axial structures that range from small deletions to embryos lacking heads. The graded series of axial defects obtained after RA administration to early embryos appears to result, in part, from actions of RA on embryonic mesoderm. RA modifies the differentiation of anterior dorsal mesoderm from animal cap ectoderm induced by mesoderm-inducing peptide growth factors (PGFs). Concentrations of RA that suppress anterior dorsal mesoderm result in the differentiation of mesoderm of more posterior or ventral character. The suppression of anterior dorsal mesoderm may account for the absence of anterior neural ectoderm after RA treatment. Although RA changes the character of mesoderm, it does not seem to affect mesodermal induction by PGFs or the levels of Xhox 3 mRNA induced in the mesoderm by PGFs. RA therefore appears to affect steps downstream from those involved in the initial induction of mesoderm. In experiments to examine the possible physiological role of RA in early Xenopus development, dorsal and ventral ectoderm were found to respond differently to identical concentrations of PGFs. One potential basis for this heterogeneity is the existence of a localized inhibitor, possibly RA, in the early Xenopus embryo. RA could therefore contribute to axial patterning by inhibiting the development of mesoderm of different character induced by PGFs.

[Key Words: Axial patterning; embryo; mesoderm; retinoic acid; Xenopus laevis]

Received October 16, 1990; revised version accepted November 27, 1990.

The establishment of axial polarity is an early step in the organization of the vertebrate body plan. In Xenopus embryos, the generation of anterior-posterior $(\mathrm{A}-\mathrm{P})$ polarity in the mesoderm is thought to begin at the blastula stage but becomes evident only after gastrulation (Spemann and Mangold 1924; Mangold 1933; see Hamburger 1988; Ruiz i Altaba and Melton 1989cl. The embryonic mesoderm differentiates from ectodermal cells in the marginal zone of blastula-stage embryos under the control of inductive signals from prospective endodermal cells in the vegetal region (Nieuwkoop 1969). The inductive action of vegetal cells can be mimicked by several peptide growth factors (PGFs) including basic fibroblast growth factor (bFGF), transforming growth factor- $\beta 2$ (TGF- $\beta 2$ ), and activin A (Kimelman and Kirschner 1987; Slack et al. 1987; Smith 1987; Grunz et al. 1988; Rosa et al. 1988; Asashima et al. 1990; Smith et al. 1990; Sokol et al. 1990; Thomsen et al. 1990). Mesoderm-inducing signals also appear to control the regionalization of the mesoderm, resulting in the establishment of distinct cell types along the dorsal-ventral (D-V) (Smith 1987; Cooke et al. 1987; Slack et al. 1987) and A-P (Ruiz i Altaba and Melton 1989c) axes.

During gastrulation, the regional character of the dorsal mesoderm is established as it involutes and extends along the future A-P axis of the embryo. The dorsal axial mesoderm, in turn, imposes regional differences along the A-P axis of the overlying neural ectoderm (see Hamburger 1988). Arresting the extension of dorsal mesoderm at different stages of gastrulation results in a graded series of defects in anterior structures, leading to the loss of heads, in severe cases (Gerhart et al. 1984). A comparable loss of anterior structures is caused by exposure of early embryos to UV light /Grant and Wacaster 1972; Malacinski et al. 1977; Scharf and Gerhart 1983; Cooke and Smith 1987) and by overexpression of the Xenopus homeo box gene Xhox3 (Ruiz i Altaba and Melton 1989b). Normal anterior development can therefore be arrested by several different manipulations that perturb the differentiation of anterior dorsal mesoderm.

The patterning of many embryonic tissues has been shown to be sensitive to retinoic acid (RA). In particular, local administration of RA affects the axial pattern of developing limbs (Niazi and Saxena 1978; Tickle et al. 1982; Maden 1983; Kim and Stocum 1986) and possibly also the chick blastoderm (Mitrani and Shimoni 1989). There is evidence for the presence of endogenous RA, distributed unevenly along the A-P axis of the chick limb with its high point in the posterior region (Thaller and Eichele 1987). Thus, RA may function as an endogenous morphogen involved in tissue patterning. The existence of RA receptors that act as ligand-dependent transcrip- 
tional regulators (Giguere et al. 1987; Petkovich et al. 1987) suggests that RA exerts its morphogenetic functions by regulating the expression of downstream genes.

RA administration to early Xenopus embryos causes a marked loss of anterior structures (Durston et al. 1989; Sive et al. 1990). The effects of RA on normal development, together with biochemical evidence for the presence of endogenous retinoids (Durston et al. 1989), raise the possibility that RA has a role in pattern formation in early Xenopus embryos. The RA-induced loss of anterior structures has been suggested to result from an A-P transformation of the neural ectoderm (Durston et al. 1989|. Consistent with this, RA has been shown to perturb some aspects of ectodermal development, particularly the formation of the cement gland (Sive et al. 1990). However, the anterior defects obtained after exposure of early Xenopus embryos to RA could result, additionally, from a change in the properties of embryonic mesoderm. The finding that axial defects can be produced by short periods of RA administration to early blastula embryos (Durston et al. 1989; Sive et al. 1990) at a stage when mesoderm but not neural ectoderm has differentiated supports this possibility. Moreover, RA is known to affect mesodermal development in several species (MarinPadilla 1966; Maden 1984; Tickle et al. 1989).

In this paper we present evidence that the loss of anterior structures caused by RA may be mediated through actions on the mesoderm and discuss the potential contribution of endogenous retinoids to axial patterning in early Xenopus embryos.

\section{Results}

\section{$R A$ perturbs different morphogenetic processes during} embryogenesis

Exposure of Xenopus embryos to RA results in a marked perturbation of axis formation, which becomes apparent as a deletion of anterior structures in tadpole-stage embryos (Durston et al. 1989). To begin to examine the mechanisms underlying the deletion of anterior structures, we applied RA to Xenopus embryos at different stages of development. In most cases, treated embryos were allowed to develop to tadpole stages for assessment of abnormalities.

Treatment of embryos prior to gastrulation with $10^{-9}$ to $10^{-7} \mathrm{M}$ RA resulted in a progressive deletion of anterior structures (Fig. 1A). Low concentrations $\left(10^{-9}\right.$ to $10^{-8} \mathrm{M}$ ) caused defects in the most anterior structures, usually the cement gland and forehead. Treatment with higher concentrations $\left(10^{-7} \mathrm{M}\right)$ resulted in the complete absence of a head. In addition, the posterior region of embryos was severely truncated, possibly because of effects of RA on tailbud development. Truncated embryos still exhibited a notochord and somites, although both tissues displayed abnormal morphology (not shown). These observations are consistent with previous findings (Durston et al. 1989; Sive et al. 1990). Embryos treated continuously with $10^{-7} \mathrm{M}$ RA from the early gastrula
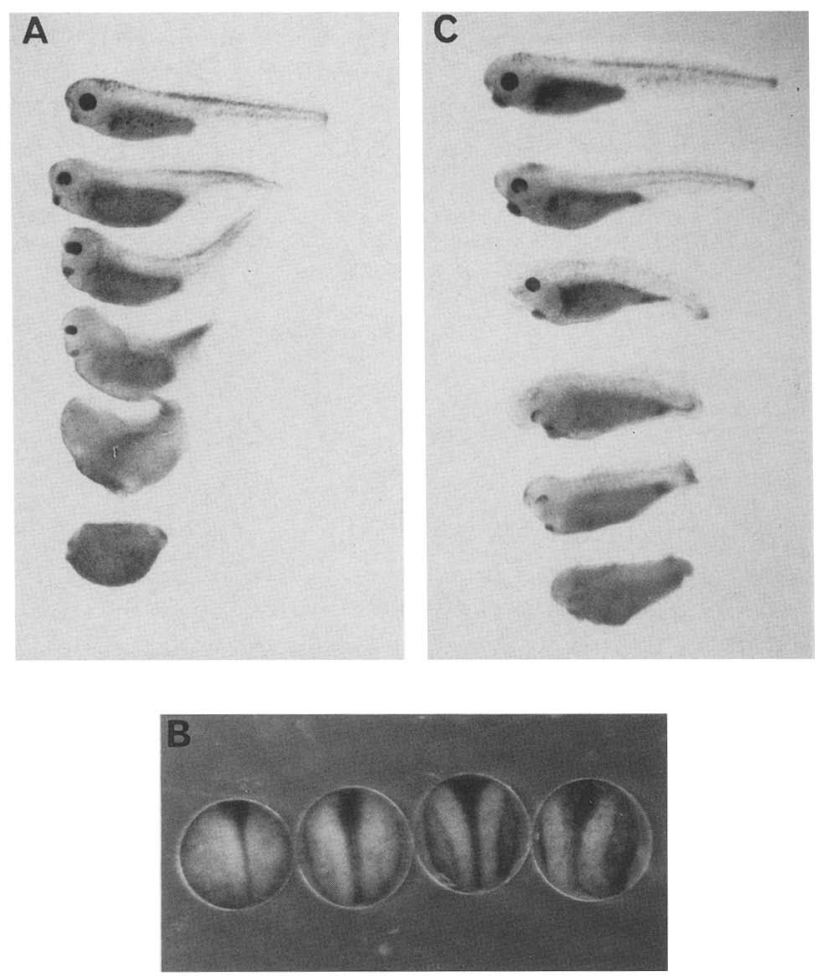

Figure 1. RA perturbs morphogenesis when applied at different stages of development. (A) Xenopus embryos were exposed to RA $\left(10^{-7} \mathrm{M}\right)$ for varying periods of time between early blastula and early gastrula stages (second from top to second from bottom/ and allowed to develop to the tadpole stage for assessment of the phenotype. Increasing the time of exposure to RA results in a progressive loss of anterior structures, including the eyes, cement gland, and head, as well as shortening of the axis due to abnormal tailbud growth. From top to bottom, the first tadpole is an untreated control, the second was treated with RA from stage 2 to stage 4 , the third from stage 2 to stage 6 , the fourth from stage 2 to stage 8 , the fifth from stage 2 to stage 10 , and the bottom embryo was exposed continuously to RA. In the latter case, the embryo failed to undergo normal neurulation. A similar series of defects was obtained by treating early embryos with different concentrations of RA for 30-60 min at the blastula stage (not shown). (B) Early neurula (stage 13-14) control embryo (left) and embryos treated continuously with $10^{-7}$, $10^{-8}$, or $10^{-9} \mathrm{M}$ RA (right to left) were photographed at the late neurula stage, after neural tube closure in control sibling embryos (stage 18-20). Note the progressive impairment of normal neurulation with increasing concentrations of RA. The embryos are shown dorsal side up to compare the shape of the neural plate and folds. Anterior is to the top. (C) Late neurula /stage 16-18) embryos were exposed continuously to different concentrations of $\mathrm{RA}\left(10^{-9}\right.$ to $\left.10^{-6} \mathrm{M}\right)$ and photographed at the tadpole stage. From top to bottom, the first embryo is an untreated control, the second was treated with $10^{-9} \mathrm{M}$, the third with $10^{-8} \mathrm{M}$, the fourth with $10^{-7} \mathrm{M}$, and the two bottom embryos with $10^{-6} \mathrm{M}$. When applied to late stages, RA affects anterior development without causing deletions of eyes and cement glands, even in severely affected embryos (bottom). Dorsal fin and tail development are abnormal.

stage failed to undergo normal neurulation (Fig. 1A, bottom). Treatment of late gastrula- to early neurula-stage 
embryos with $10^{-9}$ to $10^{-8} \mathrm{M}$ RA (Fig. 1B) also resulted in neurulation defects including the failure of the neural folds to fuse.

Application of RA to late neurula-stage embryos produced defects that differed, in part, from those obtained after RA treatment of early embryos (see above). In particular, after late application of RA, the cement gland and eyes were always present (Fig. 1C). However, there were defects in axial elongation, which may result from a disruption of tailbud development. In addition, development of the dorsal fin was perturbed, possibly as a result of actions of RA on neural crest and epithelial cells (Lotan 1980; Sporn and Roberts 1983; Kopan et al. 1987; Sulik et al. 1988). Defects in the development and patterning of the central nervous systems (CNS) after RA treatment of neurula-stage embryos are described separately (A. Ruiz i Altaba and T. Jessell, in prep.). In this paper we have focused on the effects of RA on preneurula stage embryos.

\section{$R A$ modifies the character of mesoderm induced by PGFs}

Graded axial defects similar to those obtained after exposure of early embryos to RA have been obtained with treatments that alter the properties of axial mesoderm (Gerhart et al. 1989; Ruiz i Altaba and Melton 1990). In view of this it seemed possible that the axial defects obtained in response to RA (Fig. 1A) result from a disruption of mesodermal development rather than from a direct action on ectoderm as proposed previously (Durston et al. 19891.

To determine whether RA has direct effects on mesodermal differentiation, we examined the response of animal cap ectodermal cells to mesoderm-inducing PGFs (Smith 1989) in the presence or absence of RA. Mesoderm was classified as anterior dorsal if notochord and/or somites (axial mesoderm) developed together with anterior neural tissue (brain vesicles and/or eyes). Posterior dorsal mesoderm was characterized by the differentiation of axial mesoderm with or without posterior neural (spinal cord-like) tissue. Ventral mesoderm was identified by the presence of mesenchyme and by the appearance of vesicular structures, both in the absence of axial tissues (Slack et al. 1987; Smith 1987). The PGFs used were PIF (P388D1-derived inducing factor), an activity derived from mouse macrophage cells (Sokol et al. 1990), which has been characterized as activin A /Thomsen et al. 1990), and bFGF. Presumptive ectodermal cells were isolated from the animal cap of blastula-stage (stage 7-8) embryos and cultured in the presence of PGFs together with different concentrations of RA.

Treatment of animal cap cells with high concentrations of PIF resulted in elongation of the caps and in the differentiation of dorsal axial structures, including notochord and muscle that was often segmented (Fig. $2 \mathrm{~A}-\mathrm{C}_{\text {; }}$ see Sokol et al. 1990). At lower concentrations, the effects of PIF were similar to those of bFGF and resulted in the differentiation of dorsal posterior and ventral mesoderm (Fig. 2A and data not shown) (Smith 1987; Slack et al. 1987; Ruiz i Altaba and Melton 1989c; Sokol et al. 1990 l.

The degree of elongation and the extent of differentiation of PIF- and bFGF-induced animal caps were used as assays to evaluate the effects of RA on mesodermal development. RA alone does not induce mesodermal differentiation in animal cap cells (Durston et al. 1989; Ruiz i Altaba and Melton 1989c; Sive et al. 1990). Treatment with RA $\left(10^{-10}\right.$ to $\left.10^{-7} \mathrm{M}\right)$ at the time of PIF application resulted in a progressive decrease in the extent of axial elongation and a reduction in the extent of notochord, muscle, and melanocyte differentiation, determined histologically (Fig. 2 and data not shown). The character of mesoderm obtained by induction of animal caps with high concentrations of PIF in the presence of RA was similar to that found with low concentrations of PIF (data not shown; Sokol et al. 1990). Labeling with the muscle-specific mAb 12/101 (Kintner and Brockes 1984) revealed a marked reduction in PIF-induced dorsal mesoderm in the presence of RA (Fig. 3; Table 1). The progressive decrease in the amount of muscle (Table 1) and notochord (not shown) was accompanied by an increase in the incidence of mesenchymal tissue and vesicular structures, suggestive of ventral mesoderm (Fig. 2A-D). Even though treatment with PIF in the presence of high concentrations of RA appeared to induce ventral mesoderm (Fig. 2D), histologically identifiable neural tissue was also observed occasionally (Fig. 2E). The differentiation of ventral mesoderm induced by bFGF was not significantly affected by RA $\left(10^{-10}\right.$ to $\left.10^{-7} \mathrm{M}\right)$ although in a low percentage $(\sim 10 \%)$ of cases $\mathrm{RA}$ addition resulted in a small but detectable increase in the extent of elongation of bFGF-treated animal caps (Fig. 2A). Similar results were obtained in 10 independent experiments with at least 10 animal caps per sample. On average, $80-90 \%$ of caps responded in the manner described above. These results show that RA can alter the character of the mesoderm induced by PGFs and that the differentiation of dorsal mesoderm is most sensitive to RA.

The actions of RA may be mediated at the level of the initial response of ectodermal cells to mesoderm-inducing PGFs or at subsequent steps in the differentiation of induced mesoderm. In an attempt to distinguish these two possibilities, the order of addition of PIF and RA to animal caps was varied. When $\mathrm{RA}\left(10^{-7} \mathrm{M}\right)$ was added to animal cap cells at the same time as PIF, there was a strong inhibition of dorsal mesodermal differentiation in response to high concentrations of PIF, resulting in the differentiation of ventral mesoderm. However, these effects of RA could be partially reversed by washing RAtreated caps for 1-2 hr before addition of PIF. Thus, application of PIF after extensive washing of caps exposed to $\mathrm{RA}$ induced a greater degree of elongation and the presence of a small amount of muscle (Fig. 4A and data not shown|. In the converse experiment, we found that RA was equally effective in inhibiting dorsal mesodermal differentiation when applied coincident with or up to $2 \mathrm{hr}$ after PIF (Fig. 4B and data not shown). PIF application for a period as short as $30 \mathrm{~min}$ can induce mesoderm (Sokol et al. 1990). Moreover, the inner surface of 
Figure 2. RA modifies mesodermal induction by PGFs. $(A)$ Animal caps were isolated from blastula (stage 8) embryos and left untreated (top row) or exposed to high concentrations of PIF (middle row) or bFGF (bottom row). Caps treated with PIF elongate in a manner characteristic of anterior dorsal development (middle left), whereas caps treated with bFGF do not elongate to the same extent (bottom left). Addition of RA from $10^{-10} \mathrm{M}$ (lane 10 ) to $10^{-7} \mathrm{M}$ (lane 7) causes a progressive decrease in the elongation of caps treated with identical concentrations of PIF (middle), whereas no change in appearance is seen in bFGF-treated caps (bottom). RA $\left(10^{-7} \mathrm{M}\right)$ alone does not have any appreciable effect on animal cap cells (top right). $(B)$ Section of an animal cap treated with a high concentration of PIF. Induced caps were fixed at the equivalent of the tadpole stage (stage 30). (C) Detail of a section of a cap treated with high concentrations of PIF. Note the high degree of elongation and the differentiation of dorsal tissues, including segmented somites $(\mathrm{S})$, tail fin $(T)$, melanocytes $(M)$, and neural tissue $(N)$ at stage 36. (D) Section of an animal cap treated with a concentration of PIF identical to that in $B$, in the presence of $10^{-8} \mathrm{M}$ RA. The cap forms a less elongated structure, with vesicles surrounded by ventraltype mesenchyme (ME). (E) Detail of a section of an animal cap treated with PIF and RA $\left(10^{8} \mathrm{M}\right)$ showing neural tube-like structures $(\mathrm{N})$ that are sometimes observed inside the vesicle, surrounded by mesenchymal cells (ME). Note the pigmented epithelium in the internal canal. Muscle masses and notochord were not observed in induced caps displaying these posterior neural structures.

the animal cap, which is responsive to PGFs, seals within $1 \mathrm{hr}$ of preparing caps (data not shown), which prevents any subsequent effects of PGFs. Taken together, these experiments suggest that RA can modify the fate of cells that have already been induced along a mesodermal pathway of differentiation but do not exclude additional effects of RA on ectodermal cells.

\section{Xhox $3 \mathrm{mRNA}$ levels in the induced mesoderm are not changed by $R A$}

A phenotype similar to that obtained after treatment of early embryos with RA (Fig. 1A) is produced by overexpression of the homeo box gene Xhox3 (Ruiz i Altaba and Melton 1989b|. The coincidence of phenotypes led us to examine whether the effects of RA might be mediated by an increase in the level of Xhox3 mRNA in the mesoderm. By an RNase protection assay, we first compared the level of Xhox 3 mRNA in untreated embryos with that in embryos treated with RA. There was no detectable difference in the amount of Xhox 3 mRNA present in untreated embryos when compared with embryos treated at the late gastrula/early neurula stage (Fig. 5A).
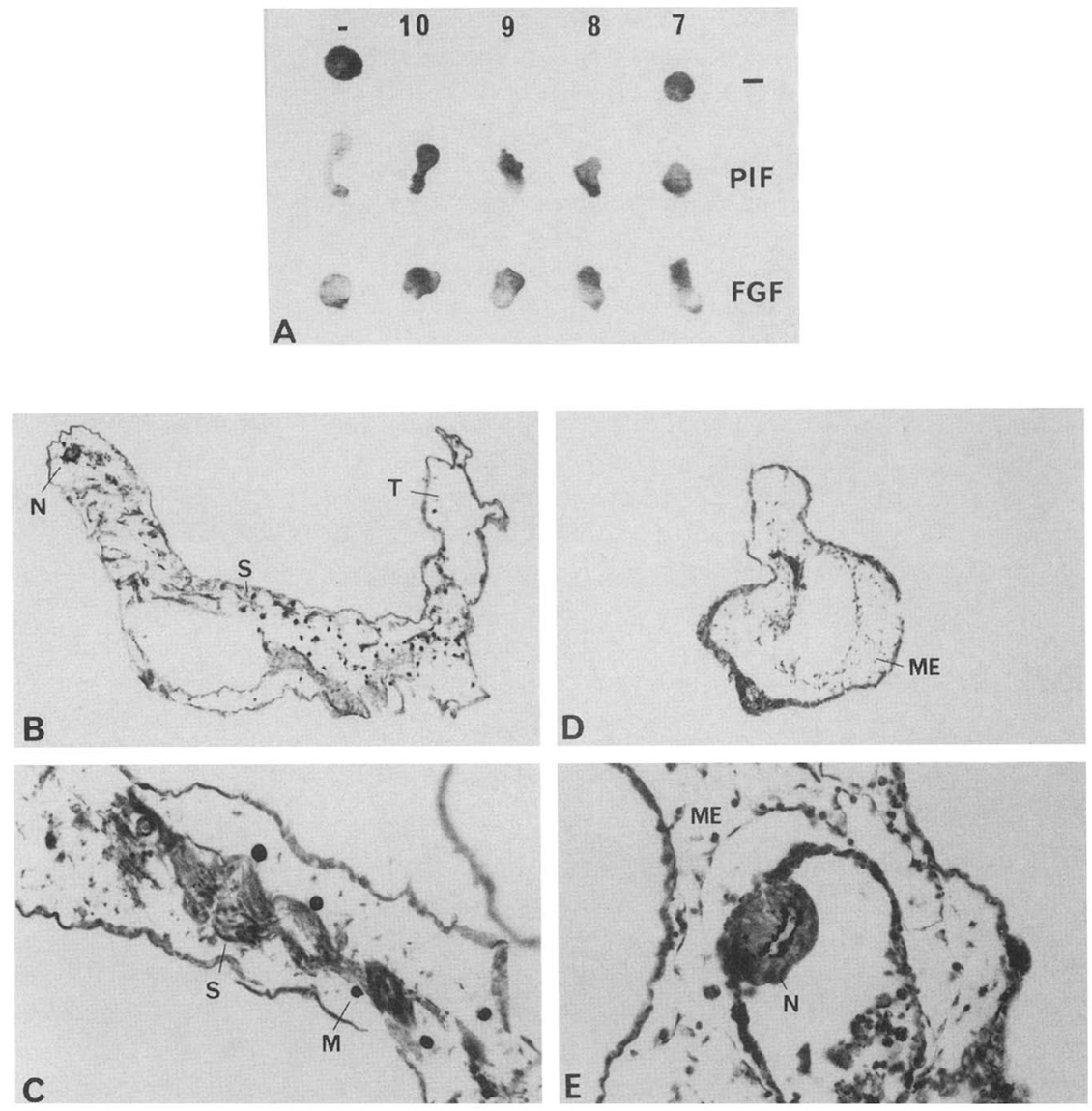

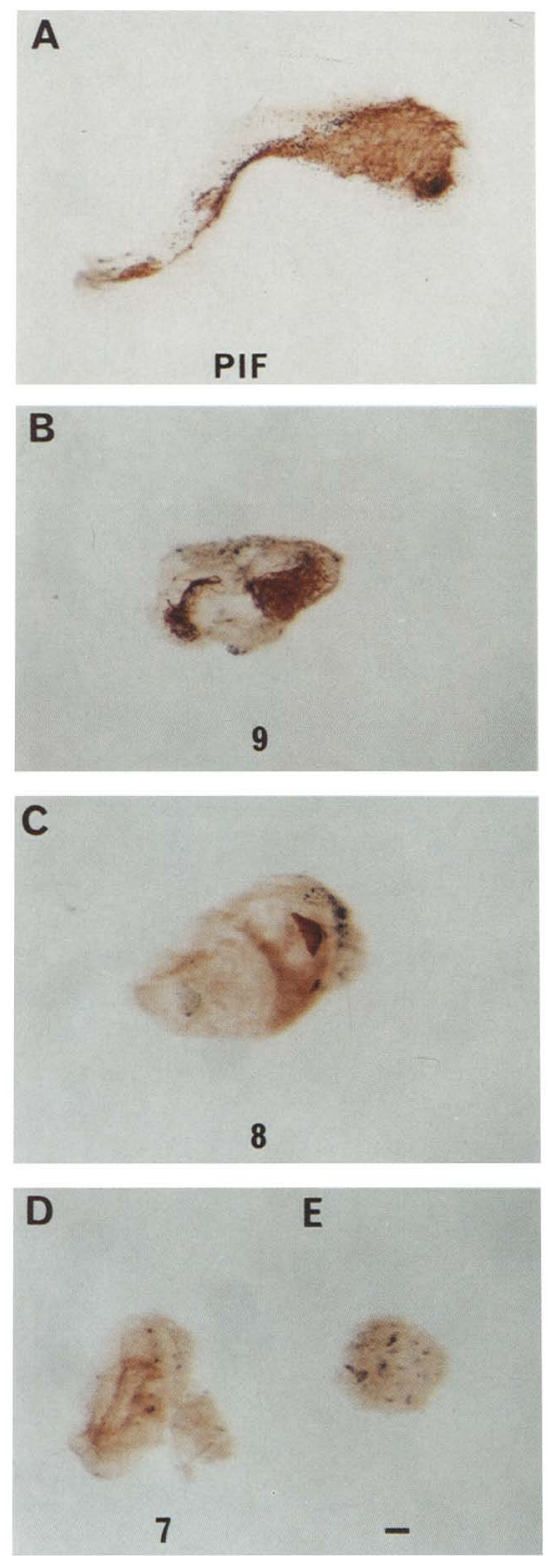

Figure 3. Effects of RA on expression of the 12/101 musclespecific antigen. Blastula-stage (stage 8 ) animal caps were isolated, induced with high concentrations of PIF in the absence $(A)$ or presence $(B-E)$ of different concentrations of RA and labeled with mAb 12/101 to detect axial muscle tissue derived from somitic mesoderm. The red-brown immunoperoxidase reaction product denotes the site of $12 / 101$ antigen expression. In the absence of RA $(A)$, PIF induces dorsal-type structures, including segmented somites. The induced animal cap shows an axial organization with A-P (right to left) and D-V (top to bottom/ polarity. Note the presence of a dorsal fin and melanocytes on top and a tail-like structure to the left. Axial organization is reduced or lost when caps are induced by PIF in the presence of $10^{-9}(B, 9), 10^{-8}(C, 8)$, or $10^{-7}(D, 7) \mathrm{M} \mathrm{RA}$. Increasing the concentration of RA reduces the number of $12 / 101$ immunoreactive cells (see Table I). In animal caps induced in the presence of $10^{-8}$ or $10^{-7} \mathrm{M} \mathrm{RA}$, isolated muscle cells are sometimes observed. Uninduced animal cap tissue does not express $12 / 101$ antigen $(E,-)$. embryonic neural tissue (Kintner and Melton 1987), decreased but did not disappear with increasing concentrations of RA (Fig. 5B). Neural induction therefore occurs in response to PIF even in the presence of high concentrations $\left(10^{-7} \mathrm{M}\right)$ of RA.

\section{$R A$ perturbs the ability of mesoderm to induce secondary structures}

The perturbation of anterior mesodermal development could be responsible for the reduction or absence of anterior structures in embryos treated with RA at early stages of development (Fig. 1A). To provide information on the possible role of RA on the differentiation of anterior mesoderm in vivo, we examined whether RA affects the ability of mesoderm to induce secondary structures after implantation into the blastocoel of gastrula-stage host embryos (Mangold 1933; Ruiz i Altaba and Melton 1989cl.

In initial experiments, anterior neural structures were induced by implanting mesoderm induced from animal cap tissue by exposure to high concentrations of PIF. In these experiments the percentage of secondary heads induced was low $(\sim 20 \%)$, and there was a high incidence $\{\sim 60 \%)$ of induced tails $(n=40$ embryos). Low concentrations of RA $\left(10^{-8} \mathrm{M}\right)$ applied to PIF-treated animal cap mesoderm completely suppressed the ability of the mesoderm to induce secondary heads (not shown), but the incidence of secondary tails remained high $1 \sim 65 \%$; $n=20$ embryos $\mid$. The prevalence of induced tails in control experiments made it difficult to assess whether the decrease in head inductions was accompanied by a significant increase in the incidence of tail inductions. A high incidence $(74 \%)$ of tails was induced after transplantation of animal cap tissue induced by bFGF $(200$ $\mathrm{ng} / \mathrm{ml})$, and this frequency was not affected by RA $\left(10^{-8}\right.$ M) (Fig. 6C; Table 2; data not shown). Transplantation of untreated animal cap tissue did not induce secondary structures (not shown; see Ruiz i Altaba and Melton 1989c).

In view of the difficulty in obtaining a large number of anterior inductions after implantation of PGF-treated animal cap tissue, we grafted prospective anterior dorsal mesodermal of stage 10 gastrulae /the Spemann organizer or dorsal lip). This region of mesoderm induces ventral ectoderm to form well-patterned heads that include anterior folds, cement gland, forebrain, and eyes in a high percentage of cases ( $\sim 80 \%$; Fig. $6 \mathrm{~A}$; Table 2 ) (Ruiz i Altaba and Melton 1990). Donor embryos were treated with RA $\left(10^{-10}\right.$ to $\left.10^{-7} \mathrm{M}\right)$ for $\sim 2 \mathrm{hr}$ before removal of the organizer. Organizers derived from donor embryos treated with RA did not induce proper head structures after implantation into an untreated gastrula-stage embryo, forming instead a head lump without cement glands or eyes (Fig. 6B; Table 2). These lumps appeared in an anterior ventral position similar to that in which heads appear after normal organizer grafts. In previous studies (Ruiz i Altaba and Melton 1989c) induced lumps have been shown to contain disorganized neural and mesodermal tissue of undetermined A-P character. No con- 
Table 1. Muscle induction in animal cap tissue in the presence of $R A$

\begin{tabular}{|c|c|c|c|c|}
\hline & Large masses & Small masses or isolated cells & No staining & $n$ \\
\hline Animal cap & 0 & 0 & 100 & 6 \\
\hline$+\mathrm{RA} 10^{-7} \mathrm{M}$ & 0 & 0 & 100 & 12 \\
\hline Animal cap + PIF & 47 & 53 & 0 & 15 \\
\hline+ RA $10^{-10} \mathrm{M}$ & 22 & 39 & 39 & 13 \\
\hline$+\mathrm{RA} 10^{-9} \mathrm{M}$ & 8 & 46 & 46 & 13 \\
\hline$+\mathrm{RA} 10^{-8} \mathrm{M}$ & 0 & 30 & 70 & 10 \\
\hline$+\mathrm{RA} 10^{-7} \mathrm{M}$ & 0 & 32 & 68 & 22 \\
\hline Animal cap + bFGF & 0 & 43 & 57 & 7 \\
\hline$+\mathrm{RA} 10^{-10} \mathrm{M}$ & 0 & 47 & 53 & 17 \\
\hline$+\mathrm{RA} 10^{-9} \mathrm{M}$ & 0 & 24 & 76 & 17 \\
\hline+ RA $10^{-8} \mathrm{M}$ & 0 & 18 & 82 & 22 \\
\hline$+\mathrm{RA} 10^{-7} \mathrm{M}$ & 0 & 45 & 55 & 11 \\
\hline
\end{tabular}

The induction of muscle in response to high concentrations of PIF or bFGF in the presence or absence of RA was assessed by staining with the muscle-specific 12/101 antibody (Kintner and Brockes 1984). Control uninduced caps were incubated alone or with RA. Explants were allowed to develop to the tadpole stage, fixed, and stained as described in Materials and methods. Muscle cells appear in isolation or as coherent muscle masses (see Fig. 3). All numbers refer to approximate percentages, with the exception of the right hand column, which refers to the number of explants $|n|$.

sistent defects were observed in any structures of the host axis following implantation of RA-treated organizers. Grafts of dorsal posterior mesoderm invariably induced posterior structures, most frequently tails, in a posterior ventral position (see also Mangold 1933; Ruiz i Altaba and Melton 1989c). These results suggest that RA can prevent normal anterior neural induction by interfering with the differentiation of prospective anterior dorsal mesoderm. However, it is not possible to exclude that the absence of induced secondary anterior structures results, in part, from actions of RA on the ectoderm after its diffusion from the implant.

\section{Differential induction of dorsal and ventral ectoderm}

The presence of RA in the Xenopus embryo (Durston et al. 1989) and the concentration-dependent effects of RA on the differentiation of PIF-induced animal cap mesoderm raise the possibility that endogenous RA might have a role in mesodermal patterning in the early embryo. Regions of ectoderm exposed to endogenous RA might respond to high concentrations of PIF by differentiating into ventral rather than dorsal mesoderm. To test this possibility, dorsal or ventral ectodermal halves of early gastrula (stage 10 to $10+$ / embryos were exposed to PIF and bFGF. Early gastrula-stage embryos were used because the appearance of the dorsal lip of the blastopore indicates reliably the dorsal side of the embryo. Dorsal and ventral animal cap halves dissected and exposed to high concentrations of PIF or bFGF did not develop identically (Fig. 7A; Table 3). Dorsal halves differentiated into anterior dorsal (head) structures in response to high concentrations of PIF, and into posterior dorsal (trunk and tail) structures in response to bFGF (see also Slack et

Figure 4. Evidence that RA directly affects mesodermal cells. Blastula-stage (stage 8) animal caps were induced to form mesoderm in the presence of a high concentration of PIF after $(A)$ or before $(B)$ exposure to $10^{-7} \mathrm{M} \mathrm{RA}$ and allowed to develop to stage 36. (A) Effects of RA addition before PIF induction. Whole embryos were treated with RA for $2 \mathrm{hr}$ and then
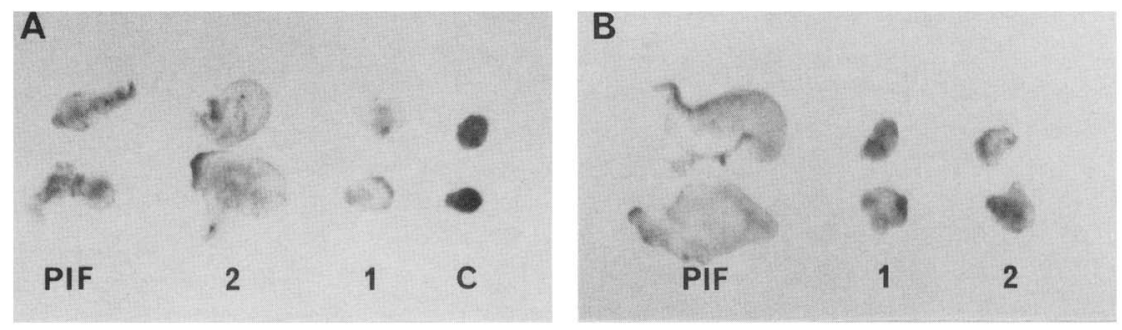
washed for 1 or $2 \mathrm{hr}$ before cutting the animal caps and exposing to PIF. The effect of RA diminishes with increasing time of washing [cf. columns 2 (2-hr wash) and 1 (1-hr wash)]. The persistence of the effect of RA may be due to storage of RA in the yolky embryonic cells or to direct effects on the uninduced ectoderm. Animal caps induced by similar concentrations of PIF without RA (left column) show dorsal tissues (including muscle and melanophores). Caps treated with RA and washed for $2 \mathrm{hr}$ (column 2) before induction by PIF form ventral-type mesodermal vesicles with some muscle. Caps treated with RA and washed for $1 \mathrm{hr}$ (column 1) before induction by PIF form ventral-type structures with mesenchyme but without muscle. Untreated caps (column $C$ ) do not develop any mesodermal tissues. (B) Effects of RA addition after PIF induction. Animal caps (stage 8) were cut, induced by PIF, and treated with RA after 1 (column 1) or $2 \mathrm{hr}$ (column 2) from the time of induction by PIF. Both RA and PIF were present for the remainder of the experiment. For comparison, induced caps in the absence of RA are shown (Ieft column). The inner surface of the animal cap, the deeper ectoderm that is responsive to PGFs, becomes inaccessible after 30-60 min, when the animal cap forms a sealed ball of cells. Similar results were obtained in five independent experiments with at least 10 animal caps per sample. 
A

B

C $\begin{array}{lll}9 & 8 & 7\end{array}$

$1 \quad 1 \quad 11$

XHOX 3

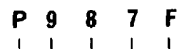

11111

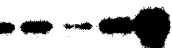

XHOX 3

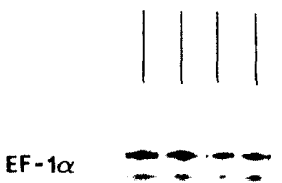

N.CAM

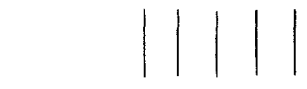

$\mathrm{EF}-10$

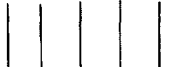

$-$

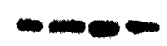

Figure 5. Xhox 3 mRNA levels in the mesoderm are not changed by RA. $(A)$ Xhox 3 mRNA levels measured by RNase protection in untreated embryos $(C)$ or after exposure to $10^{-9}$ (lane 9), $10^{-8}$ (lane 8 ), or $10^{-7}$ (lane 7) $\mathrm{M}$ RA from the early blastula to the early gastrula stage. The embryos were allowed to develop either to the early neurula (stage 15) for RNA assays or to the tadpole stage for assessment of phenotype. RA caused disturbances ranging from small anterior deletions $\left(10^{-9} \mathrm{M}\right)$ to headless embryos $\left(10^{-7} \mathrm{M}\right)$; however, the amount of Xhox 3 mRNA does not change detectably. $(B)$ Xhox 3 mRNA levels in PGF-induced animal cap cells. Dissected blastula-stage animal caps were induced to form mesoderm with bFGF $\{$ lane $F$ ) and with high concentrations of PIF (lane $P$ ) alone or in the presence of $10^{-9}$ (lane 9), $10^{-8}$ (lane 8 ), or $10^{-7}$ (lane 7) M RA. The treated caps were allowed to develop to the equivalent of the early neurula (stage 15) for RNA analysis and to the tadpole stages for assessment of the character of the induced tissue. RNase protection assays were performed to measure the levels of Xhox3 and N-CAM mRNAs and of EF- $1 \alpha$ mRNA as a uniformly expressed marker. RA treatment of PIF-induced caps changes the type of induced tissues (see Figs. 3 and 5), but the level of Xhox 3 mRNA remains at low levels characteristic of anterior dorsal development. The high level of Xhox 3 mRNA in bFGF-induced animal caps is indicative of posterior-type mesoderm (lane $F$ ). The levels of the neural-specific N-CAM mRNA are lower than those induced by PIF alone but higher than those induced by bFGF.

al. 1987; Ruiz i Altaba and Melton 1990; Sokol et al. 1990). In contrast, ventral halves responded to the same concentrations of these PGFs with the formation of ventral mesoderm similar to that obtained after induction of whole animal caps with low concentrations of PIF /Slack et al. 1987; Sokol et al. 1990; data not shown). Treatment of stage 10 dorsal animal cap ectoderm with PIF in the presence of RA $\left(10^{-10}\right.$ to $\left.10^{-9} \mathrm{M}\right)$ resulted in the induction of posterior dorsal mesoderm (Table 3). Exposure to higher RA concentrations resulted in the differentiation of mesoderm of more ventral character (not shown). Simultaneous addition of PIF and bFGF did not result in an enhancement of anterior dorsal differentiation (Table 3). Untreated dorsal and ventral halves did not develop any typical dorsal or ventral mesodermal tissues, although cement glands and melanocytes were rarely detected in
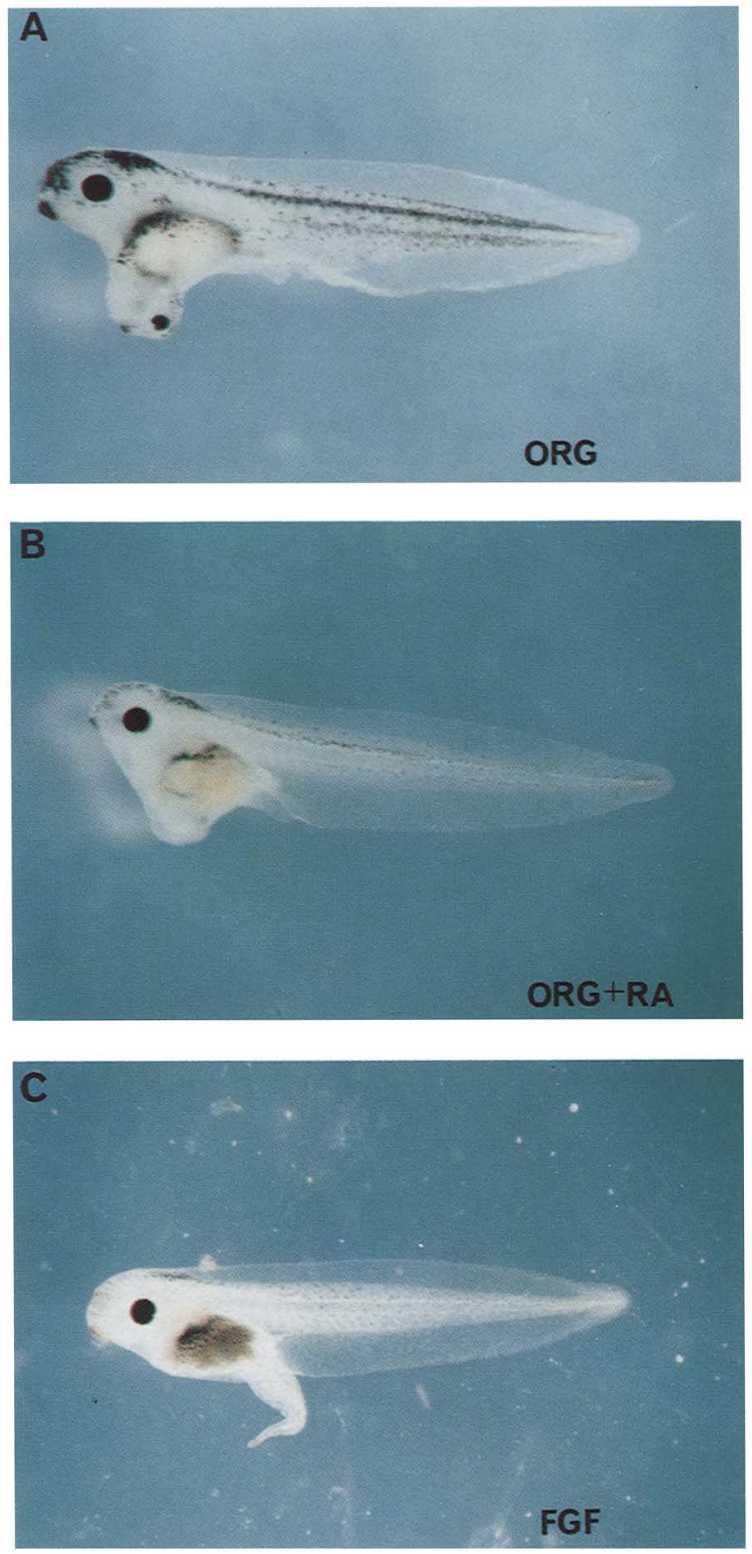

Figure 6. Effects of RA on the induction of secondary neural structures by implanted mesoderm. A group of cells from the blastopore lip of early gastrula embryos, the organizer, was implanted into the blastocoel of early gastrula-stage host embryos. Embryos were allowed to develop to the tadpole stage, and the phenotype was then assessed. (A) Implantation of an organizer results in the induction of anterior (head) neural and epidermal structures, including eyes and cement gland, in the anterior ventral area of the host. $(B)$ Organizers removed from donor embryos treated previously with RA do not induce normal head structures and instead induce an anterior lump in the anterior ventral area (see also Table 2). The inhibition of anterior differentiation by RA is not accompanied by the induction of posterior secondary structures. As control, posterior dorsal mesoderm induced from animal cap tissue exposed to high concentrations of bFGF results in the induction of posterior (tail) neural and epidermal secondary structures $(C)$.

the dorsal halves (Fig. 7A bottom). These findings provide evidence that dorsal and ventral regions of animal 
Table 2. Secondary inductions after RA treatment of implanted mesoderm

\begin{tabular}{|c|c|c|c|c|c|c|}
\hline & Head & Anterior lump & Tail & Axis & Normal & $n$ \\
\hline Organizer & 79 & 0 & 9 & 21 & 12 & 33 \\
\hline$+\mathrm{RA} 10^{-10} \mathrm{M}$ & 47 & 53 & 0 & 29 & 0 & 17 \\
\hline$+\mathrm{RA} 10^{-9} \mathrm{M}$ & 15 & 70 & 0 & 10 & 15 & 20 \\
\hline$+\mathrm{RA} 10^{-8} \mathrm{M}$ & 25 & 65 & 0 & 0 & 10 & 20 \\
\hline$+\mathrm{RA} 10^{-7} \mathrm{M}$ & 13 & 66 & 13 & 20 & 6 & 15 \\
\hline+ RA $10^{-6} \mathrm{M}$ & 0 & 95 & 0 & 0 & 5 & 19 \\
\hline bFGF animal cap & 0 & 0 & 74 & 0 & 26 & 15 \\
\hline
\end{tabular}

Prospective anterior-dorsal head mesoderm (the organizer) was excised from control donor embryos or from embryos treated with different concentrations of RA for $2 \mathrm{hr}$ (from stage 8 to stage 10) and washed briefly. Tissues were implanted in the blastocoel of host embryos. The secondary inductions were classified according to their A-P character (e.g., head vs. tail (see Fig. 6) and location along the A-P axis of the host). Note that in the cases where tails developed, a complete or partial secondary axis was also present, suggesting that the tails are not a direct result of induction by implanted mesoderm that has a posterior character. Posterior (tail) inductions in the absence of secondary axes occur after implantation of animal cap-derived posterior dorsal mesoderm induced by high concentrations of bFGF. All numbers refer to the incidence of induced structures (as a percentage), with the exception of the right hand column, which refers to number of implants $(n)$.

cap ectoderm respond differently to PIF at the early gastrula stage and that the response of ventral ectoderm to PIF is similar to that of dorsal ectoderm to PIF plus RA.

At the blastula stage (stage 8), whole animal caps in- duced by PIF formed dorsal structures including notochord and somites but not anterior neural tissue (Fig. 2). However, induction of blastula-stage ectoderm with the same concentration of PIF in the presence of RA $\left(10^{-8}\right.$ to

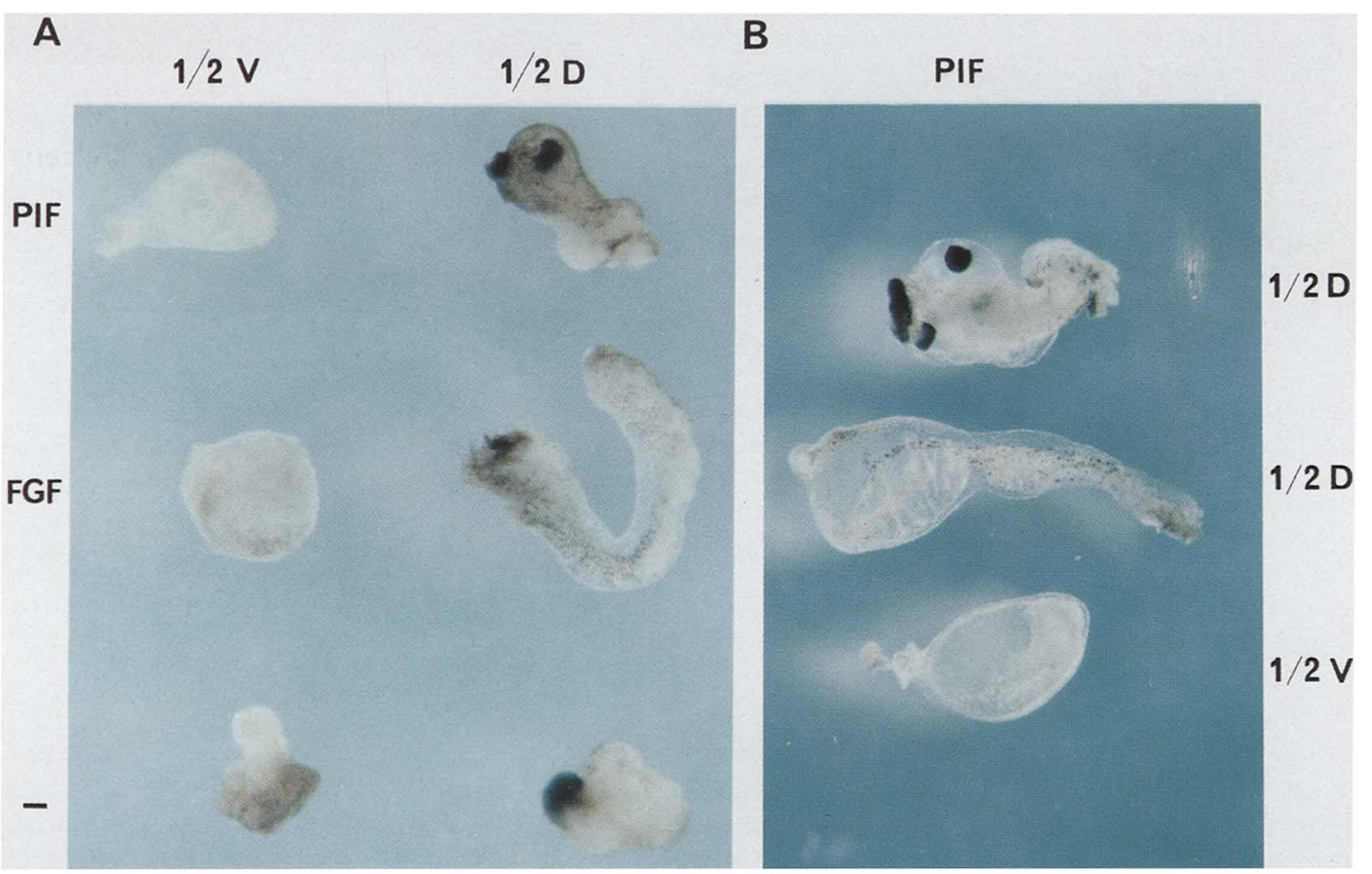

Figure 7. Differential response of dorsal and ventral ectoderm to induction by PGFs. $(A)$ Differential induction of dorsal (1/2 D column) and ventral (1/2 V column) halves of early gastrula (stage 10) animal caps. Dissected stage 10 animal caps were induced to form mesoderm by high concentrations of PIF or bFGF. As control, untreated halves were cultured to similar stages. Two examples showing the maximal degree of differentiation are shown (bottom row). Note that normally, both dorsal and ventral halves remain round and do not differentiate any recognizable structures. Dorsal and ventral halves show different responses to inducing factors. The ventral half responds to high concentrations of PIF or bFGF by forming ventral-type structures with vesicles (left), whereas the dorsal half responds to PIF with the formation of dorsal anterior (head) structures and to bFGF with posterior (trunk and tail with muscle and melanocytes) structures. Uninduced halves (bottom row) do not form any characteristic mesodermal or neural structures, although cement glands are sometimes seen. $(B)$ Mesodermal induction by PIF of dorsal halves $(1 / 2 \mathrm{D})$ resulted in the development of anterior (head with eyes) structures in $\sim 30 \%$ of the cases (see Table 3). In the remaining explants, posterior dorsal (trunk) structures developed. However, identical concentrations of PIF induce ventral mesoderm in ventral ( $1 / 2 \mathrm{~V})$ stage 10 animal cap halves. All of the induced caps derived from dorsal stage 10 ectoderm display clear A-P and D-V polarity. 
Table 3. Differential induction of dorsal and ventral ectoderm

\begin{tabular}{|c|c|c|c|c|c|c|c|}
\hline & & $\mathrm{V}$ & & & $\mathrm{AD}$ & & \\
\hline & epi & ves & axial & mel & eyes & $\mathrm{cg}$ & $n$ \\
\hline Dorsal half & 85 & 15 & 0 & 20 & 0 & 25 & 20 \\
\hline+ PIF & 0 & 12 & 67 & 85 & 30 & 50 & 40 \\
\hline+ PIF + RA $10^{-10} \mathrm{M}$ & 0 & 26 & 73 & 93 & 0 & 13 & 15 \\
\hline$+\mathrm{PIF}+\mathrm{RA} 10^{-9} \mathrm{M}$ & 0 & 33 & 66 & 80 & 0 & 0 & 15 \\
\hline+ PIF + bFGF & 0 & 27 & 60 & 80 & 20 & 27 & 15 \\
\hline+ bFGF & 22 & 33 & 39 & 28 & 5 & 39 & 18 \\
\hline Ventral half & 89 & 11 & 0 & 0 & 0 & 0 & 18 \\
\hline+ PIF & 14 & 76 & 10 & 14 & 0 & 4 & 29 \\
\hline+ PIF + bFGF & 0 & 100 & 0 & 0 & 0 & 0 & 15 \\
\hline+ bFGF & 22 & 67 & 11 & 11 & 0 & 0 & 18 \\
\hline
\end{tabular}

Stage 10 animal caps were isolated and cut into dorsal and ventral halves, with reference to the dorsal blastopore lip, and cultured alone or in the presence of different combinations of PIF and/or bFGF at high concentrations. The resulting inductions were classified according to the type of tissues produced after incubation to the equivalent of the tadpole stage (see Fig. 7). All numbers refer to incidence of induced structures (as percentages), with the exception of the right hand column, which refers to number of explants ( $n$ ). (V, PD, and AD) Ventral, posterior-dorsal and anterior-dorsal character of the induced structures, respectively. (Axial) Muscle containing inductions showing clear elongation; (cg) cement gland; (epi) atypical epidermal differentiation; (eyes) eyes with pigmented retina; (mel) neural crest-derived melanocytes; (ves) vesicles characteristic of ventral mesoderm.

$\left.10^{-7} \mathrm{M}\right)$ resulted in the differentiation of only ventral mesoderm (Fig. 2). We did not test whether D-V differences are present in the animal cap ectoderm at stage 8 or earlier, and it is therefore unclear when these differences first arise. The regional heterogeneity detected in stage 10 animal cap cells raises the possibility that the differentiation of ventral animal caps into ventral mesoderm after exposure to high concentrations of PIF results from the presence of an inhibitor of dorsal development, perhaps RA, in the ventral region.

\section{Discussion}

Exposure of early Xenopus embryos to RA has been shown to result in a concentration-dependent deletion of anterior structures (Durston et al. 1989; Sive et al. 1990). The results presented here provide evidence that such anterior deletions result, at least in part, from direct effects of RA on the development of embryonic mesoderm. RA appears to change the final character of mesoderm induced by PGFs rather than the initial steps in mesodermal induction. Taken together, our results raise the possibility that local sources of endogenous retinoids may contribute to the patterning of embryonic mesoderm by inhibiting the action of PGFs.

Several lines of evidence suggest that the early effects of RA in pregastrula embryos involve perturbation of the development of anterior dorsal mesoderm. First, the phenotype of RA-treated embryos is similar to that obtained by UV treatment (Sharf and Gerhart 1983) and Xhox3 overexpression (Ruiz i Altaba and Melton 1989b). Second, RA blocks the development of anterior dorsal mesoderm in animal cap ectoderm induced by PIF. In these experiments, addition of RA $\sim 2 \mathrm{hr}$ after exposure of caps to PIF suppressed the differentiation of anterior dorsal mesoderm, which suggests that RA acts on cells that have begun to differentiate into mesoderm. Third, RA prevented the induction of secondary heads after transplantation of PIF-treated animal cap or organizer tissue into the blastocoel of host embryos, which suggests that RA can suppress the ability of anterior dorsal mesoderm to induce anterior neural structures. In view of the low concentrations of RA used $\left(10^{-10}\right.$ to $\left.10^{-9} \mathrm{M}\right)$, the rapid rate of degradation of RA by vertebrate cells (Eichele et al. 1985), and the delay of several hours before the graft contacts the ventral ectoderm, it seems unlikely that the suppression of induced anterior structures results solely from effects of RA on the ectoderm. However, we cannot exclude the possibility that the actions of RA in these experiments are mediated, in part, by direct effects on ectodermal cells.

Although RA appears to affect the differentiation of mesoderm, the initial steps in induction of mesoderm by PGFs do not appear to be sensitive to RA. In particular, the level of Xhox 3 mRNA, expression of which is an early response to mesodermal induction (Ruiz i Altaba and Melton 1989a,c), is not significantly altered by addition of RA during mesodermal induction (Fig. 5). Thus, RA may affect mesodermal cell fate by interfering with the regulation of genes that are expressed later than $X$ hox3. Candidates include a variety of homeo box genes, which show different domains of expression along the A-P axis in Xenopus mesoderm (Harvey et al. 1986; Condie and Harland 1987; Sharpe et al. 1987; Oliver et al. 1988). Consistent with this possibility, expression of homologous mammalian homeo box genes is increased in embryonal carcinoma cells after RA treatment (Kessel et al. 1987; LaRosa and Gudas 1988; Mavilio et al. 1988; Simeone et al. 1990).

\section{$R A$ affects mesodermal cell identity}

The neural defects obtained after RA treatment of early embryos have been proposed to result from a direct effect 
of RA on neural ectoderm, giving rise to a transformation of anterior neural structures into more posterior ones (Durston et al. 1989). Our results suggest a different interpretation. The absence of anterior neural structures observed after application of RA may be secondary to a defect in axial mesodermal differentiation such that the anterior dorsal mesoderm fails to differentiate normally and therefore fails to induce anterior neural structures. The reduction or absence of anterior neural structures would thus result from a perturbation in neural induction rather than an A-P transformation of neural ectoderm.

The different mesodermal tissues that appear when animal cap cells are induced by PIF in the presence of RA indicate that RA changes the final character of the mesoderm. RA suppresses anterior dorsal mesoderm in a concentration-dependent manner resulting in the differentiation of posterior dorsal or ventral mesoderm. Although RA changes the character of mesoderm, it does not appear to undergo a complete A-P transformation. The suppression of anterior structures in embryos treated with high concentrations of RA $\left(10^{-8}\right.$ to $\left.10^{-7} \mathrm{M}\right)$ is not accompanied by the appearance of posterior structures such as tail or spinal cord in anterior regions (Fig. 1A). Moreover, RA suppresses anterior development in lithium-treated embryos but does not promote obvious posterior differentiation (data not shown).

Similarly, treatment of PIF-induced animal cap mesoderm with RA may not promote complete differentiation into ventral type mesoderm because expression of the neural marker N-CAM persists, albeit at lower levels (Fig. 5). One possible explanation for this is that the mesodermal tissues that develop in the induced animal cap in the presence of RA possess sufficient dorsal character, perhaps transiently, to induce other ectodermal cells to differentiate into neural tissue. Alternatively, PIF may be able directly to induce competent ectoderm to form neural tissue (see Sokol et al. 1990).

The development of mesoderm appears to occur in a progressive manner in response to increasing concentrations of PGFs (Smith 1989; Green and Smith 1990; Ruiz i Altaba and Melton 1990). The lowest state in this progression is ventral mesoderm with successively higher states corresponding to intermediate, posterior dorsal and, finally, anterior dorsal mesoderm (Fig. 8A). This progression may be arrested at different stages, depending on the concentration of RA, resulting in an apparent transformation in cell fate (Fig. 8B). RA may therefore contribute to mesodermal patterning by acting in a concentration-dependent manner, to inhibit the development of mesoderm of different axial character induced by PGFs.

\section{Involvement of $R A$ in axial patterning}

There is increasing evidence that RA acts as an endogenous morphogen in vertebrate embryos (Eichele 1989). The pronounced effects of exogenous RA on the patterning of early Xenopus embryos raise questions about the presence, localization, and role of RA in normal devel-
A

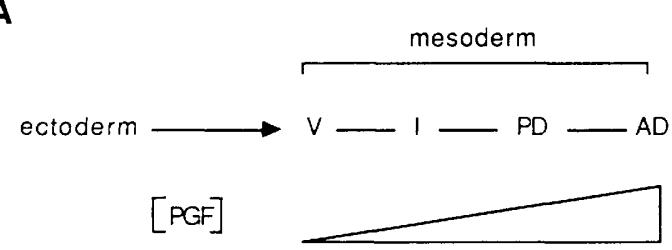

B

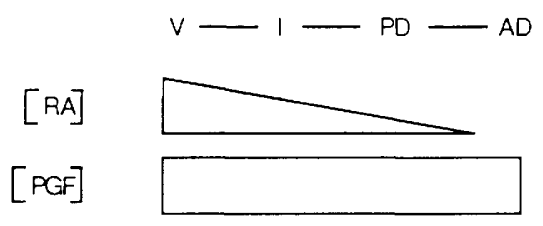

Figure 8. Schematic diagram summarizing the effects of RA on mesodermal development. (A) Mesoderm-inducing PGFs, such as PIF, induce competent ectodermal cells to become mesoderm of different axial character in a concentration-dependent manner. Low concentrations induce ventral mesoderm; high concentrations induce anterior dorsal mesoderm. $(B)$ The final character of the mesoderm induced by PGFs can be modified by RA in a concentration-dependent manner. Increasing concentrations of RA result in the differentiation of mesoderm of more posterior of ventral character from ectodermal cells that would normally give rise to anterior dorsal mesoderm in response to a high concentration of PGFs. (AD) Anterior dorsal; (I) intermediate; (PD) posterior dorsal; (V) ventral.

opment. Biochemical studies have provided evidence that RA is present in early Xenopus embryos (Durston et al. 1989|, although its localization is not known. The graded series of mesodermal cell types obtained along both the A-P and D-V axes after addition of identical concentrations of PIF and increasing concentrations of RA (Figs. 1 and 2) could result, in part, from a graded distribution of endogenous RA in the early embryo.

A local source of RA in the pregastrula embryo could act in concert with graded or evenly distributed mesoderm-inducing signals to establish different $\mathrm{D}-\mathrm{V}$ fates in the mesoderm. It could also be responsible for generating heterogeneity in the ectoderm so that by stage 10 , ventral ectoderm responds to induction by PIF with the differentiation of ventral mesodermal structures. RA may therefore be localized in ventral regions of the early pregastrula embryo. However, by the end of gastrulation (stage 13), when an implanted organizer is in contact with anterior ventral ectoderm, the grafted mesoderm can induce a normal head at a ventral position. Therefore, by the end of gastrulation the anterior ventral ectoderm may no longer contain or be exposed to an inhibitor of anterior dorsal differentiation. After gastrulation, ventral mesoderm becomes localized to the posterior region of the embryo (Gerhart and Keller 1986). Thus, a ventrally located source of RA, possibly in the mesoderm, prior to gastrulation would be localized posteriorly after gastrulation. An early ventral and later posterior 
source of RA could enhance ventral and posterior fates and repress dorsal and anterior fates in a concentrationdependent manner.

There is evidence that the heterogeneity detected within stage 10 ectoderm may also depend on other localized signals. For example, signals deriving from the organizer region may spread through the adjacent ectoderm to induce (Spemann 1938; Sharpe et al. 1987; Dixon and Kintner 1989; Savage and Phillips 1989| and pattern (Ruiz i Altaba 1990) neural tissue. The differences in dorsal and ventral ectoderm observed at the beginning of gastrulation could result from several distinct signals, for example, one that originates from the ventral region and biases ectoderm toward ventral differentiation, and a second that originates from the organizer (dorsal) region and biases the ectoderm toward dorsal differentiation. The establishment of early regional differences in the neural ectoderm by such graded signals \{Ruiz i Altaba 1990) could explain the high degree of organization that is observed after induction of whole animal caps with mesoderm-inducing PGFs /Cooke et al. 1987; Slack et al. 1987; Smith 1987; Green et al. 1990; Sokol et al. 1990). Induction by PGFs may reveal a latent heterogeneity or prepattern in the animal cap, which gives rise to the development of mesodermal and neural structures with clear D-V and A-P polarity. Evidence consistent with this idea has been obtained independently (S. Sokol and D.A. Melton, pers. comm.).

Endogenous RA has been implicated in the establishment of axial pattern in the mesoderm during development of the chick wing bud (Tickle et al. 1982, 1985, 1989; Summerbell 1983; Eichele et al. 1985; Thaller and Eichele 1987; Wagner et al. 1990). Moreover, in amphibians, exogenous RA can affect all three axes in the regenerating limb, changing the fates of mesodermal cells to more proximal posterior and ventral values (Niazi and Saxena 1978; Maden 1983, 1984; Stocum and Thoms 1984; Kim and Stocum 1986; Ludolph et al. 1990). RA may therefore have a similar role in mesodermal patterning at distinct times during development, first during gastrulation and later during limb morphogenesis.

\section{Materials and methods}

\section{Materials}

Xenopus laevis eggs were obtained from female frogs injected with human chorionic gonadotropin. The eggs were fertilized in vitro with testis homogenates. Embryos were reared in $0.1 \times$ MMR (Newport and Kirschner 1982) and staged according to Nieuwkoop and Faber (1967). All-trans-RA (Sigma) was stored as a $10^{-3} \mathrm{M}$ stock in DMSO and diluted into $0.1 \times$ MMR. PIF derived from P388D1-conditioned media was a gift of S. Sokol and D.A. Melton. PIF was used at $1: 1$ dilution (high concentration) and $1: 10$ dilution (low concentration) in $0.5 \times \mathrm{MMR}$ unless otherwise stated. About $2 \mathrm{hr}$ after addition of PIF, the medium was exchanged for fresh $0.5 \times$ MMR containing penicillin and streptomycin. Recombinant bFGF was used at a concentration of $50 \mathrm{ng} / \mathrm{ml}$ unless otherwise indicated. Blastocoel transplantation experiments and tissue isolation were performed as described (see Ruiz i Altaba and Melton 1989c).

\section{Hybridization assays}

RNase protection assays with Xhox 3 (Ruiz i Altaba and Melton 1989a), N-CAM (Kintner and Melton 1987), and EF- $1 \alpha$ (Krieg et al. 1989) DNA probes were performed as described (Ruiz i Altaba and Melton 1989a). Ten, eight, and one embryo or animal cap equivalents were used for the Xhox3, N-CAM, and EF-l $\alpha$ probes, respectively. Exposure times were 4 days for detection of $X$ hox 3 and N-CAM-protected bands, and $30 \mathrm{~min}$ for the EF-l $\alpha$ band.

Whole-mount antibody staining and histology

Animal caps were fixed in $3.7 \%$ formaldehyde, 1 mM EGTA, 1 $\mathrm{mM}$ magnesium sulfate, and $0.1 \mathrm{M}$ MOPS buffer (pH 7.4) (Patel et al. 1989| for $30 \mathrm{~min}$. Staining with the muscle-specific $\mathrm{mAb}$ 12/101 (Kintner and Brockes 1984) was performed as described (Dent et al. 1989). For histological sections, fixed embryos were embedded in paraffin, and $10-\mu \mathrm{m}$-thick sections were cut and stained with Giemsa.

\section{Acknowledgments}

We are grateful to S. Sokol and D. Melton for the gift of PIF and for communicating unpublished results. We thank C. Kintner, D. Melton, G. Struhl, and members of the Jessell and Dodd labs for comments on the manuscript. A.R.A. was supported by a Howard Hughes Medical Institute fellowship. T.M.J. is a Howard Hughes Investigator.

The publication costs of this article were defrayed in part by payment of page charges. This article must therefore be hereby marked "advertisement" in accordance with 18 USC section 1734 solely to indicate this fact.

\section{Note added in proof}

Sequence data described in this paper have been submitted to the EMBL Data Library.

\section{References}

Asashima, M., H. Nakano, K. Shimada, K. Kinoshita, K. Ishii, H. Shibai, and N. Ueno. 1990. Mesodermal induction in early amphibian embryos by activin A /erythroid differentiation factor). Wilhelm Roux's Arch. Dev. Biol. 198: 330-335.

Condie, B.G. and R.M. Harland. 1987. Posterior expression of a homeobox gene in early Xenopus embryos. Development 101: 95-105.

Cooke, J. and J.C. Smith. 1987. The mid-blastula cell-cycle transition and the character of mesoderm in UV-induced nonaxial Xenopus development. Development 99: 197-210.

Cooke, J., J.C. Smith, J. Emma, and M. Yaqoob. 1987. The organisation of mesodermal pattern in Xenopus laevis: Experiments using a Xenopus mesoderm-inducing factor. Development 101: 893-908.

Dent, J.A., A.G. Polson, and M.W. Klymkowsky. 1989. A wholemount immunocytochemical analysis of the expression of the intermediate filament protein vimentin in Xenopus. Development 105: 61-74.

Dixon, J.E. and C.R. Kintner. 1989. Cellular contacts required for neural induction in Xenopus embryos: Evidence for two signals. Development 106: 749-757.

Durston, A.J., J.P.M. Timmermans, W.J. Hage, H.F.J. Hendriks, N.J. de Vries, M. Heideveld, and P.D. Nieuwkoop. 1989. Retinoic acid causes an anteroposterior transformation in the 
developing central nervous system. Nature 340: 140-144.

Eichele, G. 1989. Retinoids and vertebrate limb pattern formation. Trends Genet. 5: 246-251.

Eichele, G., C. Tickle, and B.M. Alberts. 1985. Studies on the mechanism of retinoid-induced pattern duplications in the early chick limb bud: Temporal and spatial aspects. I. Cell Biol. 101: 1913-1920.

Gerhart, J. and R. Keller. 1986. Region-specific cell activities in amphibian gastrulation. Annu. Rev. Cell Biol. 2: 201-229.

Gerhart, J. J.-P. Vincent, S.R. Scharf, S.D. Black, R.L. Gimlich, and M. Danilchik. 1984. Localization and induction in early development of Xenopus. Phil. Trans. R. Soc. Lond. Biol. Sci. 307: 319-330.

Gerhart, J., M. Danilchik, T. Doniach, S. Roberts, B. Rowning, and R. Stewart. 1989. Cortical rotation of the Xenopus egg: Consequences for the anteroposterior pattern of embryonic dorsal development. Development (suppl.)107: 37-51.

Giguere, V., E.S. Ong, P. Segui, and R.M. Evans. 1987. Identification of a receptor for the morphogen retinoic acid. Nature 330: 624-629.

Grant, P. and J.F. Wacaster. 1972. The amphibian grey crescent region-A site of developmental information? Dev. Biol. 28: $454-471$.

Green, J.B.A. and J.C. Smith. 1990. Graded changes in dose of a Xenopus activin A homologue elicit stepwise transitions in embryonic cell fate. Nature 347: 391-494.

Green, J.B.A., G. Howes, K. Symes, J. Cooke, and J.C. Smith. 1990. The biological effects of XTC-MIF: Quantitative comparison with Xenopus bFGF. Development 108: 173-183.

Grunz, H., W.L. McKeehan, W. Knochel, W. Born, J. Tiedemann, and $\mathrm{H}$. Tiedemann. 1988. Induction of mesodermal tissues by acidic and basic heparin binding growth factors. Cell. Differ. 22: 183-190.

Hamburger, V. 1988. The heritage of experimental embryology. Hans Spemann and the Organizer. Oxford University Press, Oxford.

Harvey, R.P., C.J. Tabin, and D.A. Melton. 1986. Embryonic expression and nuclear location of Xenopus homeobox (Xhox) gene products. EMBO /. 5: 1237-1244

Kessel, M., F. Schulze, M. Fibi, and P. Gruss. 1987. Primary structure and nuclear localization of a murine homeodomain protein. Proc. Natl. Acad. Sci. 84: 5306-5310.

Kim, W.S. and D.L. Stocum. 1986. Retinoic acid modifies positional memory in the anteroposterior axis of regenerating axolotl limbs. Dev. Biol. 114: 170-179.

Kimelman, D. and M. Kirschner. 1987. Synergistic induction of mesoderm by FGF and TFG $\beta$ and the identification of an mRNA coding for FGF in the early Xenopus embryo. Cell 51: 859-877.

Kintner, C.R. and J.P. Brockes. 1984. Monoclonal antibodies identify blastemal cells derived from differentiating muscle in newt limb regeneration. Nature 308: 67-69.

Kintner, C.R. and D.A. Melton. 1987. Expression of the Xenopus $\mathrm{N}$-CAM RNA in ectoderm is an early response to neural induction. Development 99: 311-325.

Kopan, R., G. Traska, and E. Fuchs. 1987. Retinoids as important regulators of terminal differentiation: Examining keratin expression in individual epidermal cells at various stages of keratinization. J. Cell Biol. 105: 427-440.

Krieg, P.A., S.M. Varnum, M. Wormington, and D.A. Melton. 1989. The mRNA encoding elongation factor $1 \alpha(E F-1 \alpha)$ is a major transcript at the midblastula transition in Xenopus. Dev. Biol. 133: 93-100.

LaRosa, G.J. and L.J. Gudas. 1988. Early retinoic acid-induced F9 teratocarcinoma stem cell gene ERA-1: Alternate splicing creates transcripts for a homeobox-containing protein and one lacking the homeobox. Mol. Cell Biol. 8: 3906-3917.

Lotan, R. 1980. Effects of vitamin A and its analogs (retinoids) on normal and neoplastic growth. Biochim. Biophys. Acta 605: 33-91.

Ludolph, D.C., J.A. Cameron, and D.L. Stocum. 1990. The effect of retinoic acid on positional memory in the dorsoventral axis of regenerating axolotl limbs. Dev. Biol. 140: 41-52.

Maden, M. 1983. The effect of vitamin A on the regenerating axolotl limb. I. Embryol. Exp. Morphol. 77: 273-295.

- 1984. Does vitamin A act on pattern formation via the epidermis or the mesoderm? J. Exp. Zool. 230: 387-392.

Malacinski, G.M., J. Brothers, and H.-M. Chung. 1977. Destruction of components of the neural induction system of the amphibian egg with ultraviolet irradiation. Dev. Biol. 56: 24-39.

Mangold, O. 1933. Uber die Induktionsfahigkeit der verschiedenen Bezirke der Neurula von Urodelen. Naturwissenschaften 21: 761-766.

Marin-Padilla, M. 1966. Mesodermal alterations induced by hypervitaminosis A. J. Embryol. Exp. Morphol. 15: 261-269.

Mavilio, F., A. Simeone, E. Boncinelli, and P.W. Andrews. 1988. Activation of four homeobox gene clusters in human embryonal carcinoma cells induced to differentiate by retinoic acid. Differentiation 37: 73-79.

Mitrani, E. and Y. Shimoni. 1989. Retinoic acid inhibits growth in agarose of early chick embryonic cells and may be involved in regulation of axis formation. Development 107: $275-280$.

Newport, J. and M. Kirschner. 1982. A major developmental transition in early Xenopus embryos II. Control of the onset of transcription. Cell 30: 687-696.

Niazi, I.A. and S. Saxena. 1978. Abnormal hindlimb regeneration in tadpoles of the toad (Bufo andersoni) exposed to excess vitamin A. Folia Biol. (Crakow) 26: 3-11.

Nieuwkoop, P.D. 1969. The formation of mesoderm in urodelean amphibians. I. Induction by the endoderm. Wilhelm Roux's Arch. EntwMech. Org. 162: 341-373.

Nieuwkoop, P.D. and J. Faber. 1967. Normal table of Xenopus laevis (Daudin). North Holland, Amsterdam,

Oliver, G., C.V.E. Wright, J. Hardwicke, and E.M. DeRobertis. 1988. Differential antero-posterior expression of two proteins encoded by a homeobox gene in Xenopus and mouse embryos. EMBO 1. 7: 3199-3209.

Patel, N.H., E. Martin-Blanco, K.G. Coleman, S.J. Poole, M.C. Ellis, T.B. Kornberg, and C.S. Goodman. 1989. Expression of engrailed proteins in arthropods, annelids and chordates. Cell 58: 955-968.

Petkovich, M., N.J. Brand, A. Krust, and P. Chambon. 1987. A human retinoic acid receptor belongs to the family of nuclear receptors. Nature 330: 444-450.

Rosa, F., A.B. Roberts, D. Danielpour, L.L. Dart, M.B. Sporn, and I.B. Dawid. 1988. Mesoderm induction in amphibians: The role of TGF- $\beta 2$-like factors. Science 329: 783-785.

Ruiz i Altaba, A. 1990. Neural expression of the Xenopus homeobox gene $X$ hox 3 : Evidence for a patterning neural signal that spreads through the ectoderm. Development 108: 595604.

Ruiz i Altaba, A. and D.A. Melton. 1989a. Bimodal and graded expression of the Xenopus homeobox gene Xhox3 during embryonic development. Development 106: 173-183.

. 1989b. Involvement of the Xenopus homeobox gene $X$ hox 3 in pattern formation along the anterior-posterior axis. Cell 57: 317-326.

. 1989c. Interaction between peptide growth factors and homeobox genes in the establishment of anterior-posterior polarity in frog embryos. Nature 341: 33-38. 
1990. Axial patterning and the establishment of polarity in the frog embryo. Trends Genet. 6: 57-64.

Savage, R. and C.R. Phillips. 1989. Signals from the dorsal blastopore lip region during gastrulation bias the ectoderm toward a nonepidermal pathway of differentiation in Xenopus laevis. Dev. Biol. 133: 157-168.

Scharf, S.R. and J.C. Gerhart. 1983. Axis determination in eggs of Xenopus laevis: A critical period before first cleavage, identified by common effects of cold, pressure and ultraviolet irradiation. Dev. Biol. 99: 75-87.

Sharpe, C.R., A. Fritz, E.M. DeRobertis, and J.B. Gurdon. 1987. A homeobox-containing marker of posterior neural differentiation shows the importance of predetermination in neural induction. Cell 50: 749-758.

Simeone, A., D. Acampora, L. Arcioni, P.W. Andrews, E. Boncinelli, and F. Mavilio. 1990. Sequential activation of HOX2 homeobox genes by retinoic acid in human embryonal carcinoma cells. Nature 346: 763-766.

Sive, H.L., B.W. Draper, R.M. Harland, and H. Weintraub. 1990. Identification of a retinoic acid-sensitive period during primary axis formation in Xenopus laevis. Genes \& Dev. 4: 932-942.

Slack, J.M.W., B.G. Darlington, J.K. Heath, and S.F. Godsave. 1987. Mesoderm induction in early Xenopus embryos by heparin binding growth factors. Nature 326: 197-200.

Smith, J.C. 1987. A mesoderm-inducing factor is produced by a Xenopus cell line. Development 99: 3-14.

Smith, J.C. 1989. Mesoderm induction and mesoderm inducing factors in early amphibian development. Development 105: $665-677$.

Smith, J.C., B.M.J. Price, K. Van Nimmen, and D. Huylebroeck. 1990. Identification of a potent Xenopus mesoderm-inducing factor as a homologue of activin A. Nature 345: 729-731.

Sokol, S., G. Wong, and D.A. Melton. 1990. A mouse macrophage factor induces head structures and organizes a body axis in Xenopus. Science 249: 561-564.

Spemann, H. 1938. Embryonic development and induction. Yale University Press, New Haven.

Spemann, H. and H. Mangold. 1924. Uber induktion von embryonalanlagen durch implantation artfremder organisatoren. Wilhelm Roux's Arch. EntwMech. Org. 100: 599-638.

Sporn, M.B. and A.B. Roberts. 1983. Role of retinoids in differentiation and carcinogenesis. Cancer Res. 43: 3034-3040.

Stocum, D.L. and S.D. Thoms. 1984. Retinoic-acid induced pattern completion in regenerating double anterior limbs of urodeles. J. Exp. Zool. 232: 207-215.

Sulik, K.K., C.S. Cook, and W.S. Webster. 1988. Teratogens and craniofacial malformations: Relationships to cell death. $D e$. velopment (suppl.) 103: 213-232.

Summerbell, D. 1983. The effect of local application of retinoic acid to the anterior margin of the developing chick limb bud. J. Embryol. Exp. Morphol. 78: 269-289.

Thaller, C. and G. Eichele. 1987. Identification and spatial distribution of retinoids in the developing chick limb bud. $\mathrm{Na}$ ture 327: 625-628.

Thomsen, G., T. Woolf, M. Whitman, S. Sokol, J. Vaughan, W. Vale, and D.A. Melton. 1990. Activins are expressed early in Xenopus embryogenesis and can induce axial mesoderm and anterior structures. Cell 63: 485-493.

Tickle, C., B. Alberts, J. Lee, and L. Wolpert. 1982. Local application of retinoic acid to the limb bud mimics the action of the polarizing region. Nature 296: 564-565.

Tickle, C., J. Lee, and G. Eichele. 1985. A quantitative analysis of the effect of all-trans-retinoic acid on the pattern of chick wing development. Dev. Biol. 109: 82-95.

Tickle, C., A. Crawley, and J. Farrar. 1989. Retinoic acid appli- cation to chick wing buds leads to a concentration-dependent reorganization of the apical ectodermal ridge that is mediated by the mesenchyme. Development 106: 691-705.

Wagner, M., C. Thaller, T. Jessell, and G. Eichele. 1990. Polarizing activity and retinoid synthesis in the floor plate of the neural tube. Nature 345: 819-822. 


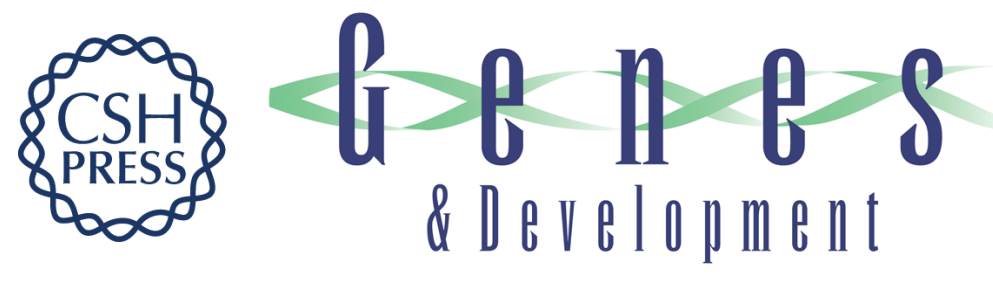

\section{Retinoic acid modifies mesodermal patterning in early Xenopus embryos.}

A Ruiz i Altaba and T Jessell

Genes Dev. 1991, 5:

Access the most recent version at doi:10.1101/gad.5.2.175

References This article cites 68 articles, 19 of which can be accessed free at:

http://genesdev.cshlp.org/content/5/2/175.full.html\#ref-list-1

License

Email Alerting Receive free email alerts when new articles cite this article - sign up in the box at the top Service right corner of the article or click here.

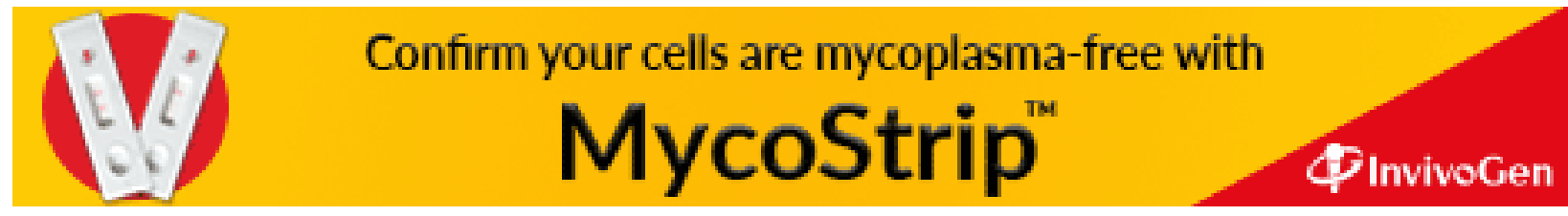

